\title{
The markers of wellbeing: A basis for a theory-neutral approach
}

\author{
Tim E. Taylor
}

\begin{abstract}
Programmes for measuring national wellbeing are challenged by the fact that there are a number of competing theories of what wellbeing consists in, and there is no prospect that the debate between them will be resolved.

Although different theories disagree about what constitutes wellbeing, I argue that there is substantial common ground on what I call the 'markers' of wellbeing: things that are either constitutive, productive or indicative of wellbeing. Whatever stands in one of these relations to wellbeing is potentially relevant to its measurement. Something that is constitutive of wellbeing according to one theory will often be productive or indicative of wellbeing according to another and thus, despite their differences, both theories may acknowledge it as a marker of wellbeing.

This paper considers which markers of wellbeing are sufficiently widely shared between different mainstream theories that they could form the basis of a theory-neutral approach to the measurement of wellbeing for the purposes of public policy. The paper defines what would count as a marker of wellbeing in this context; sets out criteria that candidate markers would need to meet; and proposes a list of nine markers that I argue are consistent with a wide range of mainstream theories and with widely-held folk assumptions about wellbeing.
\end{abstract}

Keywords: public policy, measurement, theories of wellbeing, consensus, theory-neutral

\section{Introduction}

In recent years there has been a trend for governments and international organisations to look beyond economic indicators and seek to measure national wellbeing for the purposes of informing public policy or measuring its success. ${ }^{1}$

Measuring wellbeing requires some idea of what wellbeing is and therefore what is to be measured. Programmes for measuring national wellbeing face a challenge in that there are a number of competing theories of what wellbeing consists in. There is a family of what can be described broadly as hedonist or mental-state accounts, which hold that wellbeing is constituted by affective states, or by some particular state, such as happiness or life-satisfaction, which is regarded as reflecting a person's overall evaluation of or affective response to his or her life. There are desire- or preference-satisfaction accounts, which define wellbeing in terms of the satisfaction of actual, filtered or idealised desires and/or preferences. Then there are various kinds of 'objective' accounts. These include Aristotelian accounts, which define wellbeing in terms of the perfection of human excellences and/or the development and exercise of human capacities. Objective-list accounts hold that wellbeing depends upon the possession of various prudential goods, such as health and autonomy; there are many variants, whose lists sometimes

${ }^{1}$ See Bache (2013) and Bache and Reardon (2013) for a summary of developments in the UK and Europe. 
include subjective goods such as happiness as well as objective ones. There is also the Capabilities Approach, which in its most familiar form resembles an objective-list account, albeit with Aristotelian influences and some subjective elements. There are, of course, many different variants within the broad categories of wellbeing theories discussed above. ${ }^{2}$

These many theories make different and competing claims about what wellbeing consists in. The debate between them is unlikely to be resolved in the foreseeable future. On what basis, then, are policy makers to choose between the rival theories in order to decide what it is that is to be measured? There are, broadly, two strategies that might be followed. One option is to select, or assume, a preferred theoretical approach and choose measures which are consistent with that. Thus, for example, those who rely (solely) on subjective wellbeing (SWB) measures such as the Satisfaction with Life scale (Diener et al., 1985) assume a theory of wellbeing combining lifesatisfaction with a form of hedonism, whereas the UN Human Development Index is based upon the capabilities approach. On the other hand, governments might use a more eclectic mix of different measures not tied to specific theoretical assumptions about the nature of wellbeing. This is, broadly, the approach taken by the UK's Office of National Statistics, for example, which uses 41 different measures (Randall et al., 2014).

Each approach has an obvious weakness. On the one hand, selecting a particular theoretical framework invites challenge from those who reject it. Thus, for example, advocates of the capabilities approach have criticised reliance on SWB measures on the grounds that people living in difficult circumstances may report themselves as happy, taking pleasure in small mercies (Sen 1987, 45-6).

The more broadly-based approach, on the other hand, is open to the charge of being ad hoc. Although measures may be selected for methodological reasons, such as the availability of data, in the absence of a theoretical basis for the approach there seems to be no principled basis for deciding which measures are most relevant to wellbeing. ${ }^{3}$

The aim of this paper is to provide a principled rationale for a version of the broadly-based strategy. It proposes an approach that is theory-neutral, taking advantage of common ground between different theories on what I call the 'markers' of wellbeing. I have argued elsewhere (Taylor 2014a) that, contrary to initial appearances, there is likely to be a substantial area of common ground between rival theories of wellbeing. Disagreement between the competing theories is primarily focused upon the question of what wellbeing consists in. However, it is not only constituents of wellbeing that are of interest for the purposes of measuring it in the context of public policy. Something may be relevant to wellbeing in different ways: it may be constitutive of wellbeing; it may tend to produce or promote wellbeing; or it may do neither of these things but nevertheless act as an indicator of wellbeing. Something which stands in one or other of these relationships to wellbeing may be considered a 'marker' of wellbeing. Markers of wellbeing, notwithstanding the different relationships in which they stand with respect to wellbeing itself, are all potentially relevant to its measurement. Data concerning a marker of wellbeing will facilitate the making of judgements about wellbeing itself.

When considering whether something is a marker of wellbeing, the 'bar' is set lower than when considering whether it is a constituent of wellbeing. The key criterion is not whether the thing in question makes a difference to someone's wellbeing in its own right, but whether it would be useful to gather data on it in the context of a programme to measure wellbeing for

\footnotetext{
${ }^{2}$ See the next section below for more detailed descriptions of the mainstream theories of wellbeing, with references.

${ }^{3}$ See Taylor (2014a) for a fuller discussion of the respective merits of the theory-specific and theory-neutral approaches.
} 
public policy purposes. It might be relevant in that context in virtue of being productive and/or indicative of wellbeing, even if it is not constitutive of wellbeing.

Different theories of wellbeing disagree about what constitutes wellbeing. However, for each theory it will be the case that other things beyond what it regards as constitutive of wellbeing will be either productive or indicative of wellbeing. These are likely to include things that a different theory would regard as constitutive of wellbeing. When this is the case, although the two theories will remain in disagreement about whether the item in question is a constituent of wellbeing, they can both agree that it is a marker of wellbeing. Thus, for example, health is a constituent of wellbeing according to many objective-list theories. It is not constitutive of wellbeing for hedonistic or desire-satisfaction theories. However, proponents of such theories would be likely to agree that health is productive of wellbeing, in normal circumstances. Good health is itself a subject of some of our desires, and it also facilitates (and poor health frustrates) the achievement of other desires. Similarly, all else being equal, healthy people are in general likely to be happier for it. So although only certain theories regard health as constitutive of wellbeing in its own right, a much wider range of theories - perhaps all mainstream theories (see below) - could acknowledge it as a marker of wellbeing. This paper will consider how we might identify which markers of wellbeing are sufficiently widely shared between different mainstream theories to form the basis of a theory-neutral approach to the measurement of wellbeing in the context of public policy. It will also make some suggestions as to what these might be. I do not claim that within a single article it is possible to reach complete and definitive conclusions about the markers of wellbeing. My earlier work called for further study of and debate on this issue between both philosophers of wellbeing and empirical researchers (Taylor, 2014a). To some extent, this is also a subject upon which lawmakers and policy makers will wish to make their own judgments. They will have at their disposal the literature on competing theories of wellbeing and on research about wellbeing in the social sciences, as well as the advice and data provided by their own national experts.

Nevertheless, despite these important caveats, it is possible to draw some preliminary conclusions, if not about all the markers of wellbeing, then at least about certain key markers which might form the basis of a theory-neutral approach to wellbeing in the policy context.

\section{Definition, Caveats and Clarifications}

The first step in the process of identifying markers of wellbeing is to define exactly what we are looking for. I propose the following general definition of what counts as a marker of wellbeing for present purposes:

$X$ is a marker of wellbeing if, according to all mainstream theories of wellbeing, either:

1. $X$ is constitutive of wellbeing; or

2. $X$ is something that can be regarded as reliably productive of wellbeing at the individual level; or

3. $X$ is something that can be regarded as a reliable indicator of wellbeing, at the individual level.

Note that there are different ways in which something might be constitutive of wellbeing according to a particular theory. It might be regarded as identical with wellbeing - for example, according to a hedonist theory that defined wellbeing in terms of (unadjusted) happiness, a person who is happy would ipso facto have high wellbeing. Or it might be seen as one among several constituents of wellbeing - as, for example, close personal relationships feature in many objective-list theories alongside other goods. A third, less common, relationship that holds for 
some things and for some theories is that they are regarded as necessary but not sufficient conditions for wellbeing. Thus, in Kraut's (2007: 126-30) Aristotelian theory, pleasure is a necessary but not sufficient condition for something to be considered non-instrumentally good for someone (i.e. to contribute towards their wellbeing).

Thus $\mathrm{X}$ might (according to certain theories) be either constitutive of overall wellbeing (identical with wellbeing) or one among several constituents of wellbeing, or a necessary but not sufficient condition for wellbeing. Similarly, $X$ might be productive/indicative of overall wellbeing, or it might be productive/indicative of certain (but not all) constituents of wellbeing.

Something which is one among other constituents of wellbeing, is a necessary condition for wellbeing, or is productive or indicative of one of these things, is still a marker of overall wellbeing, at least to some extent. All else being equal, someone's wellbeing will be improved for having those constituents, and one would expect some correlation between these markers and overall wellbeing. But all else will not always be equal - the presence of the relevant constituent is not sufficient to show that the person concerned has high wellbeing. For example, if someone enjoys close personal relationships, that is something which (according to certain theories) makes a positive contribution towards their wellbeing. Nevertheless, the person may have low overall wellbeing due to other factors (perhaps they are in constant pain).

In what follows it will be useful to make a distinction between, on the one hand, things which are directly constitutive, productive or indicative of overall wellbeing, and on the other, those which are partially constitutive of wellbeing (including things that are necessary but not sufficient for wellbeing), or productive or indicative of such things. Both can be considered markers of wellbeing, but I shall call the second group pro tanto markers, in recognition of the ceteris paribus condition.

A few observations, caveats and clarifications are appropriate in relation to the above definition. First, the range of actual and potential theories of wellbeing is such that it is unlikely that many, if any markers of wellbeing would be common to all possible, or perhaps even all actual, theories of wellbeing. A criterion that required a candidate marker of wellbeing to be regarded as such by all theories would be impossibly demanding. I have therefore restricted the requirement to 'mainstream' theories. I define a mainstream theory as one which is a) wellestablished - i.e. it has been around long enough to be tested through academic debate; and $b$ ) widely held (being widely held is not necessarily inconsistent with being widely rejected). There is, of course, room for debate about what it takes for a theory to count as sufficiently wellestablished and widely held. However, I suggest that the following theories (and no others), which feature widely in the literature on wellbeing, would pass this test:

1. Hedonism: The view that wellbeing is constituted by the pleasure and pain (both typically defined in a broad sense), or happiness/unhappiness (conceived as mental states, rather than as synonyms for wellbeing/illbeing itself) it contains. Recent exponents of hedonism about wellbeing include Fred Feldman (2010) and Roger Crisp (2006: 98-125).

2. Life-satisfactionism: The view that wellbeing is constituted by a person's having a positive attitude to their life - sometimes subject to conditions such as authenticity and autonomy, as in Wayne Sumner's (1996) well-known exposition.

3. Desire/preference-satisfactionism: The view that wellbeing is constituted by the satisfaction/frustration of desires or preferences. There are many variants of this approach, which can be divided into two broad camps: unrestricted theories, which include all of a person's desires, without any filter; and 
informed/rational desire theories, which focus on desires filtered by conditions of information or rationality (sometimes aetiology) or idealised desires $^{4}$ - the desires a person would have under ideal conditions, or that an ideally rational version of him/herself would have for that person. Both variants are quite widely held: The former is assumed by classical economics, the latter favoured by some philosophers.

4. Objective-list theories. These specify a list of prudential goods, and hold that wellbeing is constituted by the presence of these goods in a person's life (e.g. Finnis, 2011; Fletcher, 2013).

5. Neo-Aristotelian theories. These hold that wellbeing is constituted by the development, perfection and/or exercise of characteristic human capacities (e.g. Kraut, 2007).

I have not included the capabilities approach as a separate element, as it can be assimilated to other theories on the list. ${ }^{5}$ In its most familiar form, as expounded by Nussbaum (2000), it has an Aristotelian basis and resembles an objective-list account, but it could also be developed as a more subjective theory (Baber, 2010).

The boundaries between these theories are not always clear-cut: for example, James Griffin's version of the desire-satisfaction approach $(1986,67-8)$ includes a list of prudential goods, so is similar in that respect to objective-list theories. There are numerous variants of the different theories, and what holds true of one variant may not hold true of others.

Some explanation is needed of the terms 'reliable' and 'reliably'. It is a consequence of my approach that no marker of wellbeing will be regarded as perfectly reliable by all mainstream theories, and most will not be regarded as perfectly reliable by any theory. Even constituents of wellbeing are not perfectly reliable insofar as they are regarded as indicating overall wellbeing. Constituents of wellbeing might, however, be 100 per cent reliable as pro tanto markers of wellbeing. For example, if health is a constituent of wellbeing (e.g. on an objective-list theory), then insofar as a person is healthy, that person has better wellbeing, ceteris paribus, than if he/she had not been healthy. But being healthy is consistent with low wellbeing overall if a person lacks other constituents.

For things which are productive but not constitutive of wellbeing, there is an additional source of uncertainty. Something which is productive of wellbeing in many circumstances may not be so in others. As an example, some studies (e.g. Diener, Tay and Myers, 2011) suggest that religion tends to have a positive effect on wellbeing. However, participation in a religion is not invariably productive of wellbeing. It may sometimes have the opposite effect, as demonstrated by the unfortunate experiences of members of certain religious cults. Similarly, something which is usually an indicator of wellbeing might not always be so. So things which are productive but not constitutive of wellbeing are not 100 per cent reliable even as pro tanto markers of wellbeing.

Since no marker of wellbeing is likely to be 100 per cent reliable, a criterion which required 100 per cent reliability would be too demanding. I suggest that a marker of wellbeing can be considered 'generally reliable' if it is productive or indicative of wellbeing most of the time, in a variety of different contexts. It need not be so without exception, though if there are contexts relevant to public policy where it is in general not productive or indicative of wellbeing, that

\footnotetext{
${ }^{4}$ See Heathwood (2005) for an example of an unrestricted (or 'actualist') desire-satisfaction theory. Proponents of informed/rational desire theories include Griffin (1986), Brandt (1979) and Railton (1986).

${ }^{5}$ Insofar as it purports to be a theory of wellbeing. Proponents of the capabilities approach do not necessarily claim it as such: for example, Nussbaum (2000) sees her list of central human capabilities as reflecting a core of wellbeing, rather than the whole of it.
} 
would be a reason for excluding it. I have not attempted to quantify this to set more precise criteria for reliability: As I see it, there is no meaningful way of doing so. It is largely a matter of common sense.

The fact that no marker of wellbeing can be regarded as 100 per cent reliable - especially those which are productive or indicative, rather than constitutive of wellbeing - means that a certain caution is required in making use of these markers for policy purposes. It will be important to be alert to the possibility that in a given case they may, exceptionally, fail to be valid markers of wellbeing. It will be helpful to identify, as far as possible, the reasons why a particular factor is likely to be productive or indicative of wellbeing, and pay special attention to cases where those reasons may not present.

Having said all this, the caveat should not be overstated. I believe that the markers of wellbeing listed below are all, in fact, generally reliable.

Parts 2 and 3 of the definition talk about things which are reliably productive or indicative of wellbeing 'at the individual level'. Certain things tend to correlate with wellbeing at the level of societies rather than of individuals. Thus, for example, it may well be the case that societies with high levels of GDP tend also to be societies with high levels of wellbeing. A country's economic performance as measured by GDP may have an indirect impact on the wellbeing of individuals within it, by influencing other factors, such as income and access to healthcare, which have a more direct impact on individual wellbeing. But for a particular individual, living in a state with a high GDP is not in itself likely to be something that has a significant direct impact upon, or is directly indicative of, his or her wellbeing. Nor is the link between GDP and the other factors which do affect individual wellbeing so close that the links between these factors and individual wellbeing can be regarded as extending to GDP. Economic conditions as measured by GDP are just one among many other factors - such as social status, distribution of wealth, etc. - which influence an individual's income and access to healthcare (etc.). Similar considerations may apply to other factors which have an indirect impact upon wellbeing, such as the environment. My list of markers will include only things which can plausibly be regarded as reliably productive or indicative of wellbeing at the individual level. This is not to deny that factors such as GDP, which have an impact on overall levels of wellbeing within societies, are also important and might sensibly be included within a broadly-based approach to the gathering of data on wellbeing for policy purposes.

It should also be noted that certain factors, such as age, and genetic predispositions, may have an influence upon wellbeing (at the individual level) but are not realistically subject to influence by government policy. These might, strictly speaking, be markers of wellbeing, but they are not likely to be useful markers of wellbeing in the context of public policy (although there may be other reasons for gathering data on them). Such factors are therefore not considered in the remainder of this paper.

There is a final caveat to be noted before moving on to identify markers of wellbeing. I have proposed the theory-neutral approach in the context of the measurement of wellbeing. It might also be applicable in other contexts related to public policy. However, if the intention is not merely to measure wellbeing but to target aspects of wellbeing, then caution is required. If something is indicative, but not constitutive or productive of wellbeing, then targeting it directly is not likely to be beneficial. Suppose, for example, that it were found through empirical investigation to be the case that people who smile frequently are more likely than those who do not to score highly on various measures of wellbeing; but that smiling itself has no causal impact on other markers of wellbeing. It is thus, let us assume, indicative, but not constitutive or productive of wellbeing. If this were the case, frequency of smiling might in principle be a useful 
measure of wellbeing. However, it would not be sensible for policy interventions to target smiling directly, for example by providing medications which work on facial nerves to stimulate involuntary smiling! An increase in smiling generated by such means would not be indicative of an increase in wellbeing.

\section{Populating the list:}

\subsection{The most secure markers of wellbeing}

The mainstream theories of wellbeing listed above provide a ready list of candidate markers of wellbeing. In order to identify which markers would fit the theory-neutral approach, it is necessary to assess them against appropriate criteria. I suggest that it is sensible to use an iterative approach, whereby the most secure markers of wellbeing are identified first and others are added in subsequent phases. In later phases, empirical evidence of correlations between candidate markers and those which have already been established will be relevant to the sifting process.

To identify which candidates have the most secure claim to be considered markers of wellbeing (including pro tanto markers) in the light of the definition given above, I propose certain criteria, the first of which is: How strong a case the candidate has to be considered either constitutive, productive or indicative of wellbeing under each of the mainstream theories of wellbeing.

Among candidates which have a plausible claim to meet this criterion, all else being equal a candidate marker's claim is stronger the more widely it is regarded (among the mainstream theories) as at least partially constitutive of wellbeing, since, as discussed above, things which are constitutive of wellbeing are in general likely to be more reliable than things which are merely productive or indicative, at least as pro tanto markers.

If a programme for measuring wellbeing is to be widely accepted, not only by politicians and academics but also by the general population whose wellbeing it is seeking to measure, it needs to be recognisably measuring wellbeing, rather than something else. So it is desirable that at least some of what is measured should chime with widely held common-sense views about wellbeing. Thus, in seeking to identify the most secure markers of wellbeing, a further criterion is relevant in assessing the claims of those candidates which meet the first criterion: The extent to which the candidate fits with widely held folk assumptions about wellbeing.

I would welcome debate on which markers of wellbeing meet these criteria. In advance of such a debate, my list of proposed markers below should be seen as provisional. However, there are several candidates for which a good claim can be made. In particular, it seems to me that the following two markers have a good case to be considered particularly secure.

\subsubsection{Happiness}

The first word on anyone's lips when they are talking about wellbeing is likely to be 'happiness'. 'Happiness' is a somewhat ambiguous term. It is sometimes (for example, in translations of Aristotle) treated as a synonym for wellbeing. Sometimes it is used to describe a person's positive evaluation of or satisfaction with their life (e.g. Sumner, 1996). A third usage, related to but distinct from the second, is to refer to what is sometimes called 'positive affect' - 'feeling happy', having a positive emotional state or an overall positive balance of pleasure over pain in one's life. Here I use the term 'happiness' in this third sense. Life-satisfaction is considered in its own right as a separate marker of wellbeing below.

There are different views about what sort of affective state(s) happiness is, or incorporates some believe that it reflects the balance between pleasures and pains, with some adjustments and 
qualifications (Feldman, 2010). Others focus on emotional states considered more central than mere pleasures (Haybron, 2008). Some distinguish between different types of affective states and/or between positive and negative affect and are wary about aggregating them (Headey, Holmström and Wearing, 1984). For present purposes I am using the term 'happiness' as an overarching label to encompass a range of mental states, collections and aggregates of mental states which, notwithstanding differences of detail between them, have in common the fact that they reflect a person's generally positive affective response to their life.

Happiness in this sense is constitutive of overall wellbeing for hedonism, although some variants include conditions which happiness must meet in order to be considered constitutive of wellbeing (Feldman, 2010). It is widely acknowledged as at least partially constitutive of, or a necessary condition for, wellbeing, even by some proponents of objective theories (e.g. Kraut, 2007; Fletcher, 2013). Happiness also has a strong common-sense claim as a constituent of wellbeing. If we imagine two people whose lives are similar in all other respects, but one of them is happy and the other is not, intuitively we would tend to regard the first person as having higher wellbeing than the second.

Nevertheless, happiness would not be acknowledged as a constituent of wellbeing by all theories. Some objective-list theories do not include it. Not all Aristotelian theories regard happiness or pleasure as a necessary condition for the development and exercise of human capacities to count towards wellbeing. Desire and preference-satisfaction theories would not regard happiness as constitutive of wellbeing either.

However, there are good reasons to believe that proponents of these theories would, or should, acknowledge happiness as a marker of wellbeing. Some of our desires and preferences are for happiness, and for the positive affective states that contribute towards it. To that extent, therefore, by satisfying those desires, happiness and positive affective states are productive of wellbeing, on a desire-satisfaction theory. Psychological hedonism, the theory that all desires are for pleasure and happiness, is no longer widely accepted: some of our desires are for other things. However, a person is surely more likely to be happy if his/her desires/preferences are satisfied than if they are not. There may be exceptions (e.g. a person may believe their desires to be satisfied when they are not) but in general happiness is a good candidate to be an indicator of wellbeing, on a desire/preference satisfaction theory (Angner, 2012). It may, in particular, be an indicator of a (positive) change in wellbeing (Wren-Lewis, 2014).

I suggest that it is also likely to be the case that people who do well in terms of the stipulations of Aristotelian theories and objective-list theories (those variants that do not already include happiness or related items) - who have developed their physical and mental capacities, or possess the various objective goods listed by the theory - will tend to be happier than people who do not (at least, if the theory itself is reasonably plausible). Happiness is thus a likely indicator of wellbeing for objective theories. ${ }^{6}$

There is a potential challenge to the inclusion of happiness in this list, associated with the phenomenon of adaptation. People's emotional states adapt in various ways to the circumstances in which they find themselves. For example, situations which seem intolerable when first experienced may become less so as we grow accustomed to them. I have considered this challenge elsewhere (Taylor, 2014b). The phenomenon of adaptation is real, and implies a need for caution in measuring happiness - in particular regarding the extent to which it can be regarded as a marker of, or proxy for, overall wellbeing - but doesn't invalidate it as at least a pro

\footnotetext{
${ }^{6}$ Happiness also has a good case to be considered productive of wellbeing. There is evidence, for example, that it has a positive effect on health (Diener and Chan, 2011) - so if health itself is established as a marker of wellbeing (see below), that reinforces the case for happiness.
} 
tanto marker of wellbeing. It may sometimes be that a person's life is going less well than their level of happiness alone would suggest, but that does not imply that their being happy is not, in itself, something that has a positive effect on their wellbeing.

\subsubsection{Health}

Here I interpret the term 'health' broadly. It includes all aspects of physical health: not only freedom from disease and injury, but also adequate nutrition. It also includes mental health.

Health is a constituent of wellbeing for many objective-list theories (e.g. Finnis, 2011; Nussbaum, 2000). It also tends to be seen as an aspect of, or necessary condition for, human flourishing by Aristotelian theories (Kraut, 2007, p. 133).

General health is not regarded as constitutive of wellbeing by subjective theories, although aspects of mental ill-health which involve negative affect, such as depression, will be partially constitutive of (low) wellbeing for hedonism. However, there is a good case to consider it productive of wellbeing on subjective theories. Certain consequences of poor physical and mental health, such as physical discomfort and distress, are major sources of unhappiness and dissatisfaction. This is not to deny that people may adapt to poor health or disability and manage to achieve high wellbeing despite it. However, this is not always the case (Lucas, 2007).

Overall, good health correlates positively with happiness - and poor health negatively (Argyle, 1999; Dolan, Peasgood and White, 2008), so if happiness is established as a marker of wellbeing, that reinforces the case for health. Good health is an enabler of (and poor health an impediment to) the achievement of central life goals. Good health is for these reasons a likely object of informed/rational desire (and much actual desire).

Like happiness, health fits well with common-sense folk assumptions about wellbeing. We tend to assume that being in good health makes a difference to our quality of life.

\subsection{Other secure markers}

It seems to me that both happiness and health are strong candidates to be considered secure markers of wellbeing. Though I don't claim to have established this beyond debate, I shall treat these two markers as secure for the purposes of demonstrating my proposed iterative approach and giving some (provisional) content to the rest of the list. In considering what further markers might be included, we can add a third criterion: Evidence from empirical studies of correlations between the candidate marker and already established markers of wellbeing.

Application of this criterion, together with the other two, results in the addition of a further four markers to the list, which I also consider reasonably secure.

\subsubsection{Life-satisfaction}

As in the case of happiness, I use the term 'life-satisfaction' as an overarching label for a number of related notions which differ in detail, but share a key feature: in this case, the fact that they reflect a person's attitude to, or evaluation of, their life. This includes life-satisfaction in the strictest sense as indicated by people's scores on questionnaires, such as the Satisfaction with Life Scale (Diener et al., 1985), which invite them to rate how well statements such as 'I am satisfied with my life' apply to them. It also includes people's assessments of their lives using other methodologies, such as the ladder scale developed by Hadley Cantril (1965), which asks subjects to rate their lives on a scale between the best possible and worst possible lives.

As we have seen, life-satisfaction is sometimes identified with happiness, and is constitutive of wellbeing according to certain theories (e.g. Sumner, 1996). In other theories, it tends not to 
feature as a constituent of wellbeing. However, it is a good candidate as an indicator of wellbeing on all of the mainstream theories. A person's level of satisfaction with their life is, in effect, their own assessment of how well that life is going. It can therefore be regarded as equivalent to a firstperson judgement of wellbeing. We are not infallible judges of our own wellbeing, and thus, for theories which do not regard life-satisfaction itself as constitutive of wellbeing, it is not guaranteed to provide an accurate picture. Nevertheless, a person's own view of their wellbeing surely counts for something. Certainly, it has a strong common-sense claim to do so.

Life-satisfaction is often measured, in tandem with happiness, as the cognitive or judgemental component of subjective wellbeing, along with happiness as the affective component. Although the two may sometimes come apart (as in attitudes to income - Kahneman and Deaton, 2010) in general what increases one tends to increase the other also (Peterson, Park and Seligman, 2005). Studies also show correlations between life-satisfaction and health (e.g. Strine et al., 2008).

Like happiness, life-satisfaction is subject to the phenomenon of adaptation, arguably even more so, since it tends to involve the subject choosing a norm of what counts as satisfactory, and such norms are likely to be influenced by experience, circumstances and comparisons with others (Taylor, 2014b). As with happiness, therefore, caution is required in the use of life-satisfaction data. Nevertheless, I argue that life-satisfaction meets the criteria to be considered a marker of wellbeing.

\subsubsection{Success in realising central life goals/values}

This marker concerns the extent to which a person succeeds in securing the things they most care about, whether these be goals to which they aspire or aspects of their lives that matter to them. It is thus a form of desire/preference satisfaction, but one which reflects only those desires or preferences to which a person attributes central importance in their life. This marker is thus at least partially constitutive of wellbeing for desire/preference-satisfactionist theories of wellbeing. There are some theories for which it is wholly or largely constitutive of wellbeing (e.g. Raz, 1986, Chapter 12).

The achievement of a person's goals is also partially constitutive of wellbeing on some objective-list theories (e.g. Fletcher, 2013). It will tend to be productive (and arguably partially constitutive) of wellbeing for life-satisfaction theories: a person's evaluation of their life is likely to reflect, at least in part, how well it measures up to the goals and values that are important to them.

This marker is perhaps not quite so good a fit with hedonism and Aristotelian theories. The achievement of goals and realisation of values does not necessarily imply the development of personal capabilities, and is compatible with long periods of struggle, which might involve unhappiness, at least in the short term. Nevertheless, it is plausible that this marker is productive of wellbeing for the former and indicative for the latter, at least to some extent. In general, ceteris paribus, the achievement of goals and realisation of values is likely to be something that tends to increase happiness. And the development and exercise of capabilities is likely to facilitate the achievement of goals - and indeed, might be a goal in itself.

\subsubsection{Supportive personal relationships}

Again, I interpret this term broadly. It includes marriage, relationships with family members, friendships and even relationships with others such as neighbours and work colleagues, insofar as these can be regarded as supportive. By 'supportive', I mean that the individual derives benefit from the relationship (in its own right, rather than indirectly, as a business relationship may lead 
to financial benefit, for example). This might be in various ways: through emotional support in times of difficulty, providing companionship and (for some relationships, not others) intimacy.

Close personal relationships are partially constitutive of wellbeing for some objective-list theories (e.g. Griffin, 1996; Nussbaum, 2000). As a manifestation of social aspects of human nature, they may also be regarded as constitutive of wellbeing on some Aristotelian theories.

For subjective theories, supportive personal relationships have a strong case to be regarded as productive of wellbeing. We would expect them to be a cause of happiness and a buffer mitigating the effects of causes of unhappiness. There is indeed good evidence that supportive relationships of various kinds correlate well with other markers of wellbeing: for example, being married tends to have a positive effect on reported happiness and life-satisfaction, as well as on health (Myers, 1999). There are similarly negative correlations for divorce and widowhood.

Good relationships are also likely to be the subject of actual and informed desires and preferences. They may also, by the help we receive through them, contribute to the achievement of our goals and other desires.

\subsubsection{Personal development}

By this I mean the development, improvement and exercise of various mental and physical aspects of our natures as human beings. It includes, therefore, the development of intellectual skills and the acquiring of knowledge. This marker would also include the development of abilities associated with personality and emotion, such as leadership, courage and aesthetic appreciation; and of physical abilities, for example through sport.

Personal development, defined in various different ways, but broadly on the above lines, is constitutive of wellbeing for Aristotelian theories (e.g. Kraut, 2007). Elements related to personal development, such as knowledge, are also partially constitutive of wellbeing for some objectivelist theories (Finnis, 2011; Griffin, 1996).

For subjective theories (and some objective-list theories), personal development is in general not likely to be considered a constituent of wellbeing - although it may for some people be a focus of some of their central goals. However, it is plausibly productive of wellbeing for these theories. The development of our mental and physical abilities is likely to help us in achieving our desires, and in turn to be a source of satisfaction with our lives and of happiness.

\subsection{Further markers}

The six markers of wellbeing listed so far seem to me to be those with the strongest claims in accordance with the criteria. They are all constitutive of wellbeing according to certain theories, and plausibly productive or indicative of wellbeing for other mainstream theories. I suggest that they also chime well with common-sense assumptions about wellbeing - though the first two perhaps do better than the other four in this respect.

However these six markers are not the only ones with a reasonable claim for inclusion in the list. I conducted a further stage of the exercise, seeking to build on the most secure markers of wellbeing to find others which might be significant in the context of public policy. Whilst the most secure markers seem likely (as discussed above) to be things which fit well with commonsense intuitions about wellbeing, as the list expands new items are more likely to be things which correlate with already established markers. Thus the second criterion (the extent to which the candidate fits with widely held folk assumptions about wellbeing) becomes less important, whereas the third criterion (evidence from empirical studies of correlations between the candidate marker and already established markers of wellbeing) becomes more so. This phase of 
the process yielded a further three markers of wellbeing that seem to have a strong enough claim to be added to the list.

\subsubsection{Leisure}

By this I mean the opportunity to spend time relaxing and to pursue interests and activities beyond those required by work, or by the need to secure the essentials for human existence. It is regarded as a constituent of wellbeing by some objective-list theories (Finnis, 2011; Nussbaum, 2000). It is not generally regarded as constitutive of wellbeing by other theories. However, as an obvious source of pleasure, it has a strong case for being productive of wellbeing for hedonist theories. Many of our desires (though not always our most central ones) are focused upon leisure activities, so it seems likely to be productive of wellbeing for desire/preference-satisfactionism also. Leisure seems to correlate well with happiness (Argyle, 1999) - active leisure activities more so than passive ones such as watching TV - and with SWB more widely (Newman, Tay and Diener, 2014).

\subsubsection{Adequate income/resources}

By 'adequate' here, I mean sufficient resources to enable certain other markers of wellbeing, such as good health (which implies adequate nutrition) and achievement of personal goals, to be secured. Those resources, in most societies, will typically be in the form of income or wealth but need not always be so. For example, the members of a religious community might live in conditions where their needs are met without the need for money.

The focus on 'adequate' income or resources reflects the fact that there is evidence that income in particular (and by implication other resources too) has a much greater impact upon most other markers of wellbeing at low levels than at higher ones. Below a certain level of income/resources, people are less likely to be able to secure good health or to pursue personal goals. Income correlates well with happiness at low levels, less so at higher levels (though it correlates better with life-satisfaction (Kahneman and Deaton, 2010)). I offer no cut-off point for what level of income/resources should be regarded as adequate, as this is likely to vary between societies and between individuals.

Adequate income is not plausibly constitutive of wellbeing under any widely accepted theory (though income has sometimes been treated as a proxy for wellbeing by economists). However, as already discussed, it is an essential enabler for certain other markers of wellbeing on any mainstream theory.

\subsubsection{Rewarding employment}

I use the term 'rewarding employment' rather than simply 'employment' in recognition of the fact that employment is not always rewarding for the employee, and may sometimes - for example, when employees are exploited by employers - have a negative rather than positive impact upon wellbeing. Where both job-satisfaction and life-satisfaction are measured, there seems to be a good correlation between the two (Warr, 1999).

Rewarding employment is not constitutive of wellbeing under any plausible mainstream theory. However, it is clearly an enabler of other markers of wellbeing. This is most obviously true of income - for most people, employment is their primary source of income, either directly or indirectly through occupational pensions. Employment may also be productive of other markers of wellbeing. It may, for example, be the focus of some people's central life goals, and an environment in which close personal relationships may be formed. It might be the medium 
through which people pursue personal development. It might also be a source of happiness and life-satisfaction. These are all contingent relationships, of course, and will not always obtain. There does, however, seem to be a strong relationship between unemployment and relatively low levels of happiness and life-satisfaction (Argyle, 1999; Dolan et al., 2008).

\section{Discussion}

A list of markers of wellbeing will inevitably resemble a list of prudential goods. For this reason, the approach outlined above might, despite its 'theory-neutral' label, seem at first to amount to an objective-list approach to wellbeing; thereby attracting the opposition of those who reject this approach, especially proponents of hedonism and preference-satisfactionism. However, it is important to note that the resemblance is superficial. This is not a list of constituents of wellbeing, but of things which I argue can be recognised as either constitutive, productive or indicative of wellbeing by a wide range of theories, including hedonism and preference-satisfaction.

I see no reason why proponents of any theory of wellbeing should object to the following question: "over and above what it regards as constitutive of wellbeing, what sorts of things are likely to be generally productive or indicative of wellbeing, on your theory". Nor should they object to the idea that in the context of public policy we might attempt to identify common ground between different theories regarding the markers of wellbeing. They are, of course, entitled to disagree if they wish with my assessment of whether the things on my list would indeed tend to be productive or indicative of wellbeing if their theory is true.

Another question that arises in relation to a list of markers of wellbeing is how, in practice, governments would go about measuring them for the purposes of informing public policy. This is not an issue that I can hope to resolve in detail here: however, some general comments are appropriate.

There is already a wide range of measures relevant to wellbeing gathered both by academic researchers and by governments themselves. These comprise, on the one hand, objective measures of various aspects of human life; and on the other, subjective measures associated with what is now known as the "Science of Subjective Wellbeing". There are also hybrid measures which reflect subjective attitudes to objective aspects of life.

I suggest that a programme to measure wellbeing based upon the proposals above would select primarily from measures which are already available, though some 'tweaking' might be necessary.

Of the subjective markers on the list, happiness and life-satisfaction are extensively measured by SWB researchers using questionnaires which invite subjects to rate their happiness and satisfaction with their lives. There are various affect balance measures such as the Positive and Negative Affect Schedule (Watson, Clark and Tellegen, 1988). Success in realising central life goals/values is also covered to some extent. For example, the Satisfaction with Life Scale (Diener et al., 1985) invites subjects to rate their agreement/disagreement with various statements, one of which is: "So far I have gotten the important things I want in life".

Various measures are also available for the objective markers. Taking the UK as an example (Randall, Corp and Self, 2014), in the case of health, these include life-expectancy and reported levels of long-term illness and disability. For leisure, there are figures on participation in cultural and sporting activities. Data on leave entitlement for workers would also be relevant. National and international poverty levels provide candidate thresholds for determining adequate income.

Subjective measures are also relevant to, and available for, the more objective markers. Thus, for example, in addition to objective data, responses are gathered on satisfaction with health and with leisure. This hybrid approach is likely to be particularly important in the case of supportive 
personal relationships and rewarding employment, since objective data (e.g. on marital and employment status) is unlikely to be sufficient on its own: it matters that a person draws the support and fulfilment they need from their work and relationships.

In the case of personal development, 'eudaimonic' measures have been developed which gather data on the extent to which people are, for example, developing their potential and experiencing a sense of purpose and meaning in life (Waterman et al., 2010). Educational attainment may also be relevant to certain aspects of this marker.

Thus, in terms of their practical implications for the measurement of wellbeing, the proposals in this paper do not imply a need for radical innovation. Rather, they provide a principled rationale for a broadly-based approach to measurement, and a basis on which to select from or build upon the wide range of measures already available.

There would be many issues to consider in choosing/designing a suite of measures based upon the list of markers given above. These include, for objective measures, the question of how closely the available objective data approximates to the marker in question. For subjective measures there is the issue of how far the reliability of self-reports of happiness and satisfaction is affected by factors such as adaptation (Taylor, 2014b). These and other issues mean that there will always be some room for argument about the interpretation of data. However, I do not believe that they are an insuperable obstacle to the prospects of measuring wellbeing.

\section{Conclusions}

This paper has attempted to identify markers of wellbeing which are consistent with a wide range of mainstream theories of wellbeing and with widely held folk assumptions about wellbeing, and thus would be able to secure broad acceptance as a basis for the measurement of wellbeing in the context of public policy.

I do not regard the above list as definitive. It is relatively conservative - it includes only those items which I believe can be regarded as meeting the definition and criteria with a high degree of confidence. There are other items, such as autonomy and self-respect, for which a case could be made that they should be added to the list. I would welcome further debate on which markers of wellbeing meet the criteria set out in this paper.

A list of markers of wellbeing along these lines would support a theory-neutral approach to wellbeing in the context of public policy, and would suggest a similarly broadly-based approach to the measurement of wellbeing, involving a range of both subjective and objective measures.

A theory-neutral approach would not be without some disadvantages, in comparison with the alternative of basing the measurement of wellbeing for public policy upon a particular theory of wellbeing. As I have acknowledged elsewhere (Taylor, 2014a), the latter approach is likely to allow for a finer-grained, more determinate picture of wellbeing, with a clearer picture of the relationship between the different elements. It discriminates between what is constitutive and what is merely productive or indicative of wellbeing, whilst the theory-neutral approach does not.

On the other hand, choosing a particular theory of wellbeing as the basis for public policy renders the approach, and the choice of measures that it leads to, more open to challenge from those who reject the preferred theory - and every theory is rejected by adherents of the others. The slight loss of detail implied by a theory-neutral approach based upon markers of wellbeing that can be acknowledged from a wide range of theoretical perspectives seems to be a price worth paying for a better prospect of securing broad acceptance for the approach. 


\section{Acknowledgments}

I am grateful to Estelle Derclaye and Sam Wren-Lewis for their helpful comments on earlier drafts of this paper.

\section{Author}

Tim E. Taylor

University of Leeds

phltet@leeds.ac.uk

\section{Publishing Timeline}

Received 10 October 2014

Accepted 26 April 2015

Published 21 June 2015

\section{References}

Angner, Erik. 2012. "Subjective Well-Being: When, and Why, it Matters" (August 31, 2012). http://ssrn.com/abstract=2157140 or http://dx.doi.org/10.2139/ssrn.2157140

Argyle, Michael. 1999. "Causes and Correlates of Happiness". In D. Kahneman, E. Diener and N. Schwarz, eds. Well-Being: The Foundations of Hedonic Psychology. New York: Russell Sage.

Baber, Harriet. 2010. "Worlds, Capabilities and Well-being". Ethical Theory and Moral Practice 13: 4, 37792. http://dx.doi.org/10.1007/s10677-009-9207-1

Bache, Ian. 2013. Measuring quality of life for public policy: an idea whose time has come? Agendasetting dynamics in the European Union, Journal of European Public Policy Vol. 20, No. 1. http://dx.doi.org/10.1080/13501763.2012.699658

Bache, Ian and Louise Reardon. 2013. "An Idea Whose Time has Come? Explaining the Rise of WellBeing in British Politics". Political Studies. http://dx.doi.org/10.1111/1467-9248.12001

Brandt, Richard. 1979. A Theory of the Good and the Right. New York: Oxford University Press

Cantril, Hadley. 1965. The Pattern of Human Concerns. New Brunswick, NJ: Rutgers University Press.

Crisp, Roger. 2006. Reasons and the Good. Oxford: Oxford University Press. http://dx.doi.org/10.1093/acprof:oso/9780199290338.001.0001

Diener, Ed. and M. Y. Chan, 2011. “Happy People Live Longer: Subjective Well-Being Contributes to Health and Longevity". Applied Psychology: Health and Well-Being, 3(1), pp. 1-43. http://dx.doi.org/10.1111/j.1758-0854.2010.01045.x

Diener, Ed., R. A.Emmons, R. J. Larsen, and S. Griffin. 1985. "The Satisfaction With Life Scale”, Journal of Personality Assessment, 49, 1. http://dx.doi.org/10.1207/s15327752jpa4901 13

Diener, Ed, L. Tay, and D. Myers. 2011. "The religion paradox: If religion makes people happy, why are so many dropping out?" Journal of Personality and Social Psychology 101(6), 1278-1290. http://dx.doi.org/10.1037/a0024402

Dolan, P., T. Peasgood, and M. White. 2008. “Do we really know what makes us happy? A review of the economic literature on the factors associated with subjective well-being". Journal of Economic Psychology, 29(1), pp. 94-122. http://dx.doi.org/10.1016/j.joep.2007.09.001

Feldman, Fred. 2010. What is this thing called "Happiness". New York: Oxford University Press. http://dx.doi.org/10.1093/acprof:oso/9780199571178.001.0001

Finnis, John. 2011. Natural Law and Natural Rights, 2nd edition, Oxford: Clarendon Press.

Fletcher, Guy. 2013. "A Fresh Start for the Objective-list Theory of Well-being". Utilitas 25: 2, 206-220. http://dx.doi.org/10.1017/S0953820812000453

Griffin, James. 1986. Well-Being: Its Meaning, Measurement and Moral Importance. Oxford: Clarendon Press. Griffin, James. 1996. Value Judgement: Improving Our Ethical Beliefs. Oxford: Clarendon Press.

Haybron, Daniel. 2008. The Pursuit of Unhappiness: The Elusive Psychology of Well-Being. New York: Oxford University Press. 
Headey, B., E. Holmström, and A. Wearing. 1984. “Well-being and ill-being: Different dimensions?” Social Indicators Research 14:2, 115-139. http://dx.doi.org/10.1007/BF00293406

Heathwood, Chris. 2005. "The Problem of Defective Desires" Australasian Journal of Philosophy 83 (2005): 487-504. http://dx.doi.org/10.1080/00048400500338690

Kahneman, Daniel and A. Deaton. 2010. "High income improves evaluation of life but not emotional well-being". Proceedings of the National Academy of Sciences of the United States of America, 107 (38).http://dx.doi.org/10.1073/pnas.1011492107

Kraut, Richard. 2007. What is Good and Why? Cambridge, MA: Harvard University Press.

Lucas, Richard E. (2007). "Adaptation and the Set-Point Model of Subjective Well-Being." Current Directions in Psychological Science 16(2), pp. 75-79. http://dx.doi.org/10.1111/j.1467-8721.2007.00479.x

Myers, David. 1999. "Close Relationships and Quality of Life". In D. Kahneman, E. Diener and N. Schwarz, eds. Well-Being: The Foundations of Hedonic Psychology. New York: Russell Sage.

Newman, B., L. Tay, and E. Diener. 2014. “Leisure and Subjective Well-Being: A Model of Psychological Mechanisms as Mediating Factors". Journal of Happiness Studies 15(3), 555-578. http://dx.doi.org/10.1007/s10902-013-9435-x

Nussbaum, Martha. 2000. Women and human development: the capabilities approach. New York: Cambridge University Press. http://dx.doi.org/10.1017/CBO9780511841286

Peterson, Christopher, N. Park, and M. Seligman. (2005). "Orientations to Happiness and life satisfaction: The full life versus the empty life". Journal of Happiness Studies 6:25-41. http://dx.doi.org/10.1007/s10902-004-1278-z

Railton, Peter. 1986. “Moral Realism”. Philosophical Review 95(2), 163-207. http://dx.doi.org/10.2307/2185589

Randall, Chris, A. Corp, and A. Self. 2014. "Measuring National Well-being: Life in the UK, 2014". Office of National Statistics publication. http://www.ons.gov.uk/ons/dcp171766 352740.pdf

Raz, Joseph. 1986. The Morality of Freedom. Oxford: Oxford University Press.

Sen, A. 1987. On Ethics and Economics. Oxford: Blackwell.

Strine, Tara W., D. P. Chapman, L. S. Balluz, D. G. Moriarty, and A. H. Mokdad. 2008. “The associations between life satisfaction and health-related quality of life, chronic illness, and health behaviors among U.S. community-dwelling adults". Journal of Community Health 33(1): 40-50. http://dx.doi.org/10.1007/s10900-007-9066-4

Sumner, Wayne. 1996. Welfare, Happiness, and Ethics. New York: Oxford University Press.

Taylor, Tim. 2014a. “Towards Consensus on Well-being.” In J. Søraker. J.-W. van der Rijt, J. de Boer, P.H. Wong, P. Brey, eds. Well-Being in Contemporary Society. Cham: Springer.

Taylor, Tim. 2014b. "Adaptation and the Measurement of Well-being", Ethics and Social Welfare Vol 8 no 3 : 248-261. http://dx.doi.org/10.1080/17496535.2014.932417

Warr, Peter. 1999. “Well-Being and the Workplace." In D. Kahneman, E. Diener and N. Schwarz, eds. Well-Being: The Foundations of Hedonic Psychology. New York: Russell Sage.

Waterman, A., S. Schwartz, B. Zamboangac, R. Ravert, M. Williams, V. B. Agochae, S. Y. Kim, and M. Donnellan. 2010. "The Questionnaire for Eudaimonic Well-Being: Psychometric properties, demographic comparisons, and evidence of validity". The Journal of Positive Psychology Vol. 5, No. 1, 41-61. http://dx.doi.org/10.1080/17439760903435208

Watson, D., Clark, L. A., and Tellegen, A., 1988. "Development and validation of brief measures of positive and negative affect: The PANAS scales". Journal of Personality and SocialPsychology, 54(6), 1063-1070. http://dx.doi.org/10.1037/0022-3514.54.6.1063

Wren-Lewis, Sam. 2014. “How Successfully Can We Measure Well-being Through Measuring Happiness?" PhD Thesis, University of Leeds. 